\title{
Disaggregating Public Purposes
}

\section{Howard Husock}

Published online: 20 July 2011

(C) Springer Science+Business Media, LLC 2011

Robin Rogers has added a useful insight to the discussion of current mega-philanthropy through her use of the term philanthro-policymaking. When the Gates Foundation, for instance, uses gifts to influence New York City to open a large number of small schools, it is effectively torqueing public policy - that is, taxpayer dollars - toward its preferences. This is not a complete departure from the history of American philanthropy; Carnegie's public libraries, if accepted by local municipalities, were effectively a claim on future tax dollars for maintenance purposes.

But providing a fund for libraries was to meet an uncontroversial and relatively universal desire. Private matches for the public purse can easily be otherwise. Charter schools, for instance, whatever their virtues, prompt charged discussions about their effectiveness and appropriateness - and have, without doubt, been greatly promoted by philanthrocapitalism. As Diane Ravitch has put it “. . . the offer of a multimillion-dollar grant by a foundation is enough to cause most superintendents and school boards to drop everything and reorder their priorities.:" To underscore her view that such arrangements lack accountability-and, indeed, reflect a sort of donor conceit-she referred pointedly to their supporters (including Gates, Eli Broad, and the Walton family) as "the billionaire boys club".

Fair enough. Still, Rogers minimizes the enduring fact that voters are still free to punish officials who consort with philanthrocapitalists - and, indeed, there are no long-term guarantees when it comes to the allocation of public funds. (Outcomes tend ultimately to matter in the provision of

H. Husock $(\bowtie)$

Manhattan Institute for Policy Research,

52 Vanderbilt Avenue,

New York, NY 10017, USA

e-mail: hhusock@manhattan-institute.org public services; New York City, for instance, abandoned the Gates "small schools" experiment in the wake of unimpressive student test scores). Moreover, she overlooks another, arguably more serious threat to democratic governance posed by a key assumption of philanthrocapitalism: that if nonprofits should be guided by "business techniques", so, logically, private, for-profit enterprises should be pushed toward explicit social purposes, or at least be held to socially just standards in the way they operate. Such are the guiding principles of the "triple bottom line" to which Rogers refers, when she writes positively about "hybrid structures to create solutions to social problems."

Of course, anyone is free to try to run an enterprise that serves multiple purposes: employs the disadvantaged, cleans up the environment and earns a profit. One can wonder whether such a species can survive-what does one do, for instance, with under-performing employees? The concern about democratic governance, however, arises from the invitation such "triple bottom line" thinking provides for interest groups to pressure traditional corporations to operate in different ways. It has now become commonplace, for instance, for proxy fights to mounted for "social policy" purposes. As my Manhattan Institute colleague James Copland has noted (on the web site Proxy Monitor.Org), between 2007 and 2010, religious groups and labor unions, among others, led 215 such proxy fights directed at Fortune 100 corporations. This diverse lot included (writes Copland) "Environmental proposals have centered around encouraging companies to set greenhouse-gas emissions goals or ordering companies to issue reports on climate change/global warming or environmental sustainability. Proposals oriented around political activities have focused on forcing disclosure of corporate political contributions, trade association expenditures, or lobbying activities. Human-rights-related proposals have tended to call on corporations to establish human rights 
committees, embrace certain global human rights standards, or produce reports on human rights issues."

To many eyes, all such proposals might seem unobjectionable. But the idea that norms articulated by philanthropically-supported non-profit groups should be embraced (or, more likely, forced upon) for-profit enterprises ignores the fact that not only are such matters contentious (because of their cost implications, for instance) but that they are properly and historically the province of legal regulation-in other words, the product of political decision-making and (crucially) compromise.

In contrast, the demands of interest groups seek to hold enterprises to goals set in a vacuum and enforced through a threat of unfavorable publicity or even product boycott. Moreover, such demands are part of a serious, international movement - that of corporate social responsibility. "CSR" programs can be widely found in the academy and throughout the world. The Sao Paulo-based nongovernmental organization, Ethos Institute, for instance, has become widely known for calling on businesses to agree to hew to environmental standards. (Its projects, for instance, include, a "Business Network for Sustainability"). An argument can be made that, in the developing world, states are too week or corrupt to establish and enforce meaningful regulation of such kinds. Still, this is a slippery slope. When "philanthro-regulators", if you will, take it upon themselves to set standards, the question arises as to whom they are accountable.
In short, Rogers' not unfounded concern about the implications for democratic governance of philanthrocapitalism should rightly lead to scrutiny, as well, of the idea that philanthropic aims should be merged with traditional corporate goals (profit maximization; shareholder value). In this context, it is well worth noting that, notwithstanding the philanthropic bona fides which have accrued to Facebook founder Marc Zuckerberg for his $\$ 100$ million gift to aid the Newark (NJ) public school system, the social benefits of such "giving back" is likely to pale in comparison to the unplanned but powerful boost given the pro-democracy movement in Egypt by its use of Facebook as an organizing tool. (So high-profile was Facebook in that effort that Egyptians are apparently naming their children "Facebook"!). It is a reminder that, when one sweeps away the rumination about philanthropy and capitalism, one need not set out, self-consciously, to achieve a social good to actually do so.

Although Rogers gives only passing mention to the view of the Ford Foundation's Michael Edwards in favor of "going back to a system in which a civic space is distinct from market and government", this time-tested approach may well be the most prudent.

Howard Husock is vice president for policy research at the Manhattan Institute, where he is also director of its Social Entrepreneurship Initiative. He is a City Journal contributing editor. 